\title{
THEORETICAL FRAMEWORK FOR RESTRUCTURING OF TRANSITION COUNTRIES
}

\author{
Manuela Tvaronavičienė \\ Vilnius Gediminas Technical University, Sauletekio al. 11, LT-10223 Vilnius-40, Lithuania \\ E-mail:manuela@post.omnitel.net
}

Received 7 January 2004; accepted 27 February 2004

\begin{abstract}
The aim of the paper is to elaborate a theoretical framework for further formulating of efficient state policy in such strategic field as reconstructing of transition country's economy. The main question, which has been arisen, is: to what extent tendencies of restructuring processes are determined by consistent patterns of development. Another target of article is to discuss how far benchmarking attempts could be used in the process of choosing concrete economic policy of transition country.
\end{abstract}

Keywords: structure of economy, benchmarking, state economic policy

\section{Introduction}

Structure of economy is unanimously perceived by economists as one the most important determinants of economic development (Ishicawa (1992)); Cornwall J. Cornwal W. (2002); Hu, McAleer (2004)). States, belonging to group, called by us as "developed countries" followed natural rout of transformation and adaptation of their economies to conditions, which have been dictated by market forces. Other countries inherited economy structures, which could be treated as distorted from the point of market economy.

Hence, not accidentally, previous centrally planned countries at the very beginning of their transition way started formulation of their economic policies trying to implement certain vision of more efficient structure economies, "jumping over" this way missed stage of natural development. Alas, trying to perform this, from the first glance natural and rather clear task, governments, including Lithuanian, encountered with a lot of questions about future vision of more efficient economic structure. Finally, it clearly occurred that answers to those questions are topical issue and, actually, condition state policy of transition country. Even more, general approach to development vision determines how competitive country will be in the long term.

It is necessary to emphasize, that jeopardy in this process lies in the undercounting consistent patterns of transforming of economic structures, what could lead to economic policies duplicating natural processes or simply retarding natural growth of certain sectors of economy.

Hence, in our paper we adopt the following approach: restructuring processes should start from discussing consistent patterns of development of economies. Determination of benchmarking role in the process of seeking efficient economic structure of transition country has been seen as consistent part of theoretical framework for constructing of any grounded state economic policy in the field of its restructuring. 


\section{Restructuring, its tendencies and determinants}

To eliminate any misunderstandings, let's start from accurate identifying of target of our research. Restructuring, in principle, could be seen as phenomenon, embracing set of quantitative changes with variety of qualitative facets, starting from shifts in ownership, adopting of different organizational and integration patterns within organizations, and followed by new forms and quality of education, infrastructure etc. Despite of importance of all listed and related aspects of restructuring, we need to admit that analysis of such broadly understood issue is fraught with measurement problems and too complicated to come to explicit conclusions. Hence, we are going to narrow the scope of issue and underpin considerably simplified but statistically measurable approach to restructuring of countries' economy.

At first, we are going to clarify, what exactly, for this research purposes, is to be considered under economy structure. From the point of official statistics, economy is seen, as being comprised of its components, usually called sectors". "Sectors", in its' turn could be analyzed narrowly as parts of industries, or more widely as industries, depending on purpose. In our analysis we will take more generalized look at economy's structure and distinguish only main sectors of economy: industry, services and agriculture.

After agreeing on level of generalization of "sectors", on which emphasis would have been put, let's identify approach to the measurement of structural changes. Structural changes mean change in relative size of the sectors, which could be measured by different means. We can use size of output (contribution to Gross Domestic Product (GDP)), or by inputs used, either capital or labor. Some authors claim that more attention should be paid to labor because of interest in employment and also because it is more easily measured than capital (Griffits, Wall (2001)). Not going into deep discussion over this matter we'll use two dimensions: production and employment across the broadest economy sectors.

According, view expressed by European Bank for Reconstruction and Development (EBRD) (ERBD (1999)), "one of distinctive features of centrally planned economies was the degree of overindustrialization, compared with market economies at similar per capita income". Remarkably, that the latter opinion represents quite unanimous and unchangeable during the most intensive transition time approach to this characteristic feature of former centrally planned economies (e.g., ERBD (1997)). A primary reason for this overindustrialization has been found in "the bias of central planners in favor of the production and investment goods" and in "widening gap in manufacturing between market and centrally planned economics as a result of low innovation in the latter" (EBRD (1999)). Similar approach towards reasons of overindustrialization could be found in other papers too (Mickiewitz, Zalewska. (2002)).

The analysis of further trends of restructuring of transition economies could be based on following considerations. On the one hand, the tendency towards deindustrialization seemed to be conditioned by previous overindustrialization patterns. On the other hand, analysis of objective factors influencing structure of transition economies should signal how far this process should go.

Not going deep into elaborate discussion, we wanted to outline major tendencies of developed economies changes and distinguish driving forces of it. Evidence for the industrial countries suggests that the share of production in GDP changes according inverse " $U$ " shape pattern: at first reaches its peak ant later starts to fell down, it means, economy starts to deindustrialize. The Rowthorn-Wells model was developed as a response to the decline of industry share experienced by developed, western economies in the 1970s and 1980s. The model contributed to the extensive debate on the role and optimal speed of deindustrialization of western economies. (Rowthorn, Ramaswarmy (1997)).

The debate continues now including the postcommunist countries. Rowthorn and Wells argue that long-term structural change is driven by two factors, such as improvement in productivity at different rates across sectors (lowest for services), and differences in income elasticity of demand (with the demand for food being income-inelastic).

These two factors are sufficient to explain the longterm dynamic structural evolution. It first results in the phase of industrialization (both, the shares of industry and services in employment growing at cost of agriculture) and then in the phase of deindustrialization (service sector employment growing at the expense of industry).

Thus, Rowthorn and Wells conclude that the underlying pace of productivity change in different sectors is the major driving force of structural change. To put it in other way - main driving forces of resource reallocation among economic sectors are productivity changes, which affect the structure of aggregate demand and stimulate the creation of new sectors.

Mickiewitz and Zalewska (Mickiewitz, Zalewska 
(2002)) place the post-communist transition in the broader context of this long-term model. They argue that because communist countries have been characterized by an exceptionally high share of industry compared with the other middle-income economies, an intensive process of deindustrialization should be expected. They also claim, that, finally, structural development of transition countries may depend on the initial level of country's development by physical and human capital accumulated but also can be a function of efficiency and consistency of market reforms.

\section{Benchmarking of transition economies structures}

A lot of scientific literature is devoted to benchmarking of transition economies structures. Winiecki compares the structure of employment in socialist countries at similar levels per capita income and finds that the former are biased towards industry against services (Winiecki (1988)) Jakman and Pauna compare the structure of employment in the CEE countries to EU member countries by distinguishing the latter into northern and southern group by the relative importance of agriculture in them (Jackman, Pauna (1995)). Relative to either of the two benchmarks, CEE economies are characterized by excessive industrial and agricultural employment.

Analysis of country's restructuring process is more efficient when comparing it to processes, occurring in its political and economical "neighbors", having similar economic history and adequate future objectives. Therefore, survey of Lithuania' structural changes requires reference to a broader context of ten Central and Eastern European acceding candidates. Structural benchmarks could be rather useful in measuring Lithuania's progress in its restructuring process and finding explainable contribution of existing economical structure to aggregate economic growth. Let's look at main trends of sectoral employment distribution in 10 accession candidates, illustrating economic development pattern of Rowthorn-Wells (1987), and adopting its statements to statistical data.

Raiser et al. (2002) assume that sectoral employment share reflects the overall country's structure of output, thus concentrating on the labor movements across sectors during the transitional path. According to them, the structural characteristics of employment are one of the main indicators of a country's employment, occupational categories, education, human capital and distribution of skills are factors commonly taken as indicators of a country's place on an evolutional ladder. In conformity with these statements, authors form a benchmark of employment distribution in agriculture, industry and market services of 50 market economies in 1995. The 50 market economies include 14 of the $15 \mathrm{EU}$ member states, omitting only Luxembourg. This model is further applied in evaluating dynamics of labor reallocation process in 10 newly associated EU members. Important restriction of this model is that static employment structure of market economies in 1995 is benchmarked, although analysis of employment structure in Newly Associated Members includes period 1995-2000. During five years period the benchmark itself would have been changed and data of acceding candidates'employment distribution in 2000 is orientated backwards to 1995 benchmark of 50 market economies. Also benchmarked market economies shouldn't represent the exact direction and pace of labor reallocation for their Eastern European neighbors as plausible deviations from the benchmark could occur due to each country's specifics.

However, apart of the before-mentioned restrictions, the main aim of the benchmark is to reveal the common trends of employment distribution among economic sectors, measuring the intensity of restructuring process, which occurred in Eastern European acceding during their transition as well as the distance of their employment structures' from that of typical market economies.

From Figure 1 it is evident that all 10 accession candidates are moving towards benchmarked structure of employment during transition period. Red curve shows the level of employment in 50 market economies in three main sectors - agriculture, industry and service sectors. Black curves show dynamics of employment in main economic sectors of Eastern European countries as their economies grow in terms of GDP.

Figure 1 presents evidence that pre-transition level of employment in industry was too expanded of all accession countries. Right-side downward slope reflects GDP decrease associated with transition period and economic crisis, while approximately from 1995 all transition countries experienced economic upturn and increase of industrial labor productivity. Thus decrease in industrial employment, or in economic terms - deindustrialization - occurred, although even in year 2000 any country reached benchmarked level of market-economy industrial employment.

Figure 2 illustrates, that accession candidates began the transition with agricultural labor force that was 
relatively small compared to market economies of comparable incomes. Agriculture's share of total employment continued to decline, remoting the market economy benchmark, though by 2000 the rate of decline slowed down considerably.

If the eight more rapid and advanced reformers excluding Bulgaria and Romania - are examined, the average share of employment in agriculture was 10.9 per cent, ranging from 5-7 per cent in the Czech Republic and Slovak Republic to 19-20 per cent in
Lithuania and Poland. To put in other way, these 8 accession candidates already have agricultural labor forces that are comparable to that of lower income EU member states. Although Figure 2 reveals lower than benchmark's Lithuania's share of agricultural employment, comparing it to the GDP share of agriculture, it's evident that this sector employs excessive labor force, which isn't productive enough to increase agriculture's contribution to country's economic growth.

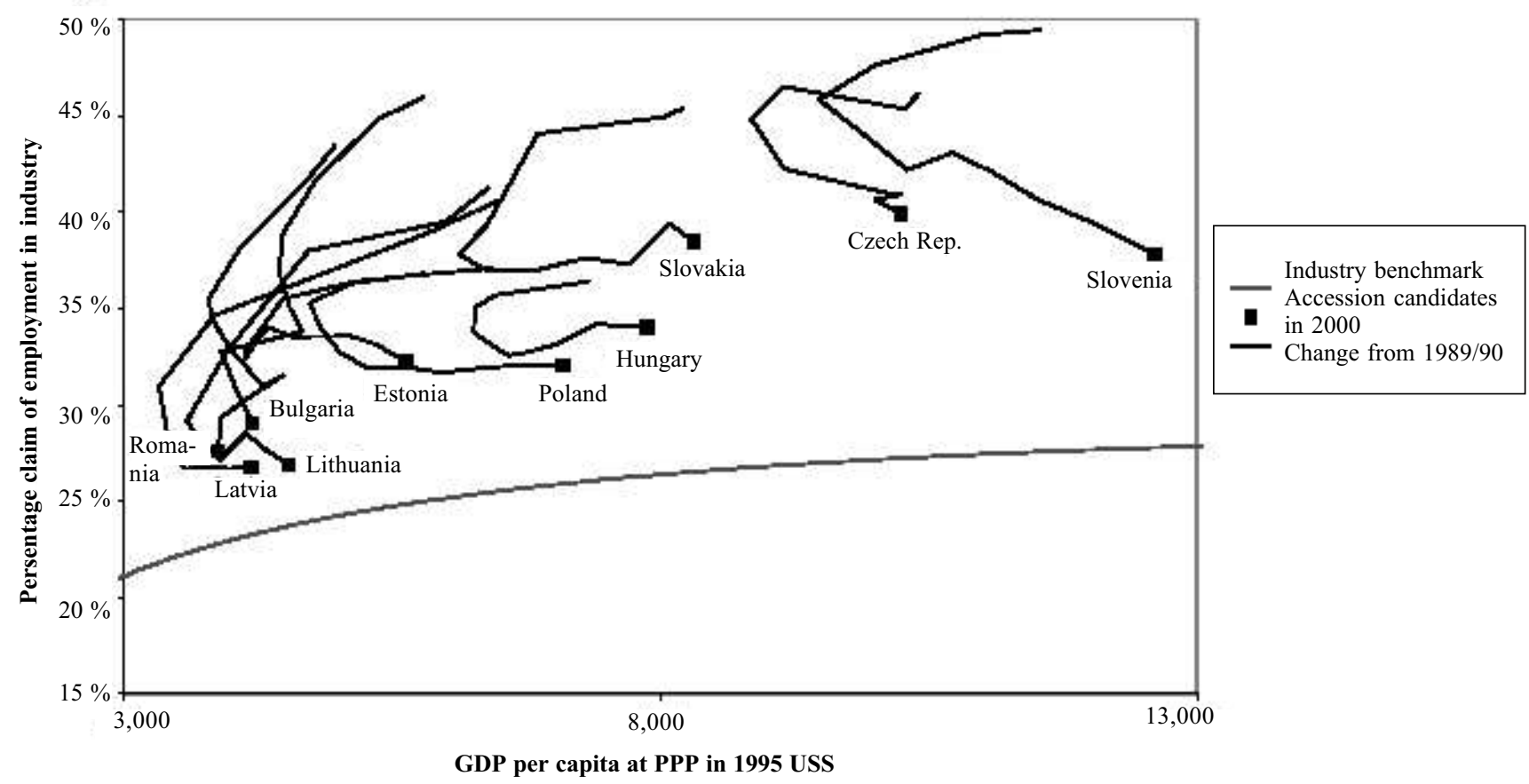

Fig 1. Dynamics of industrial employment in Accession Candidates in 2000 and change from Pre-transition

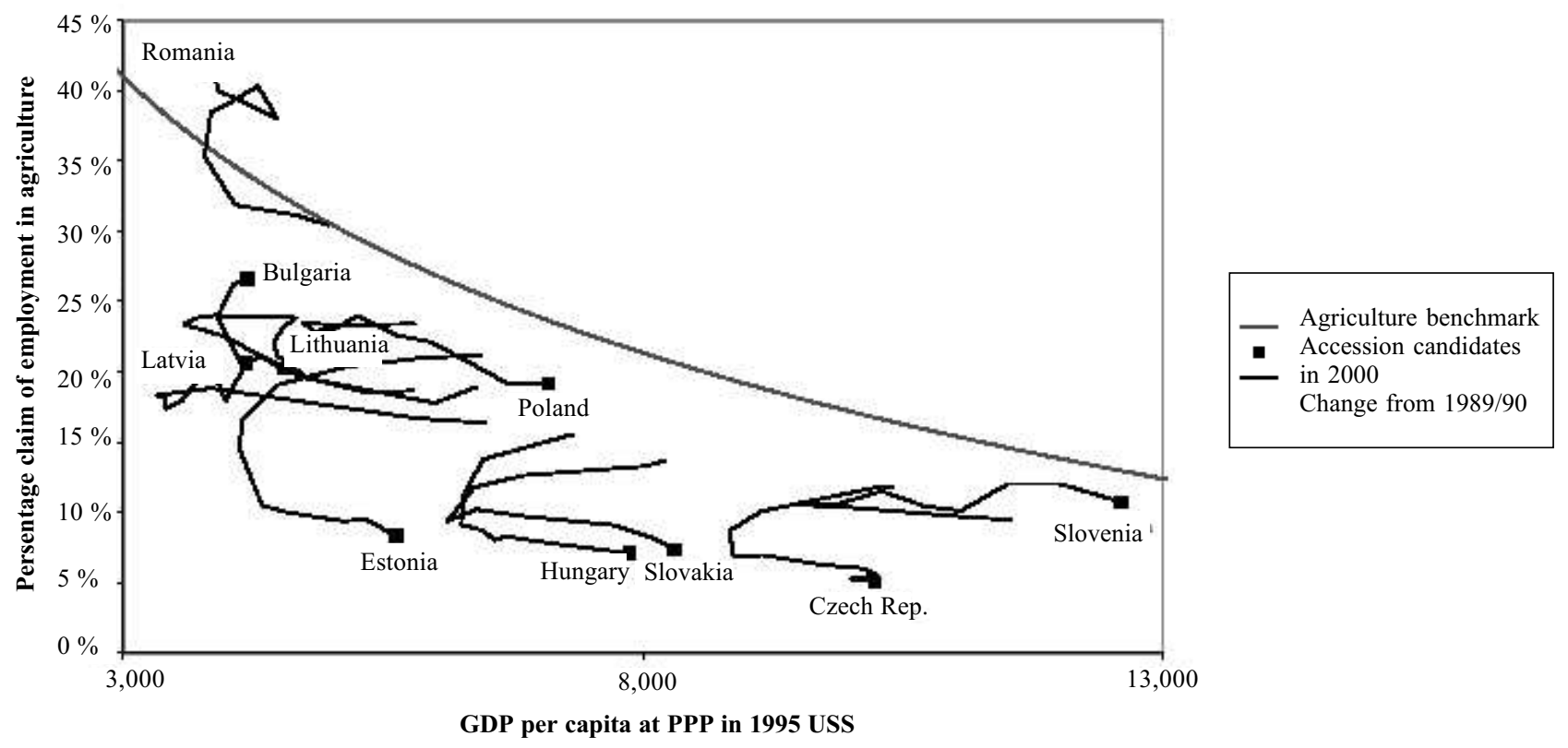

Fig 2. Dynamics of agricultural employment in Accession Candidates in 2000 and change from pre-transition. 


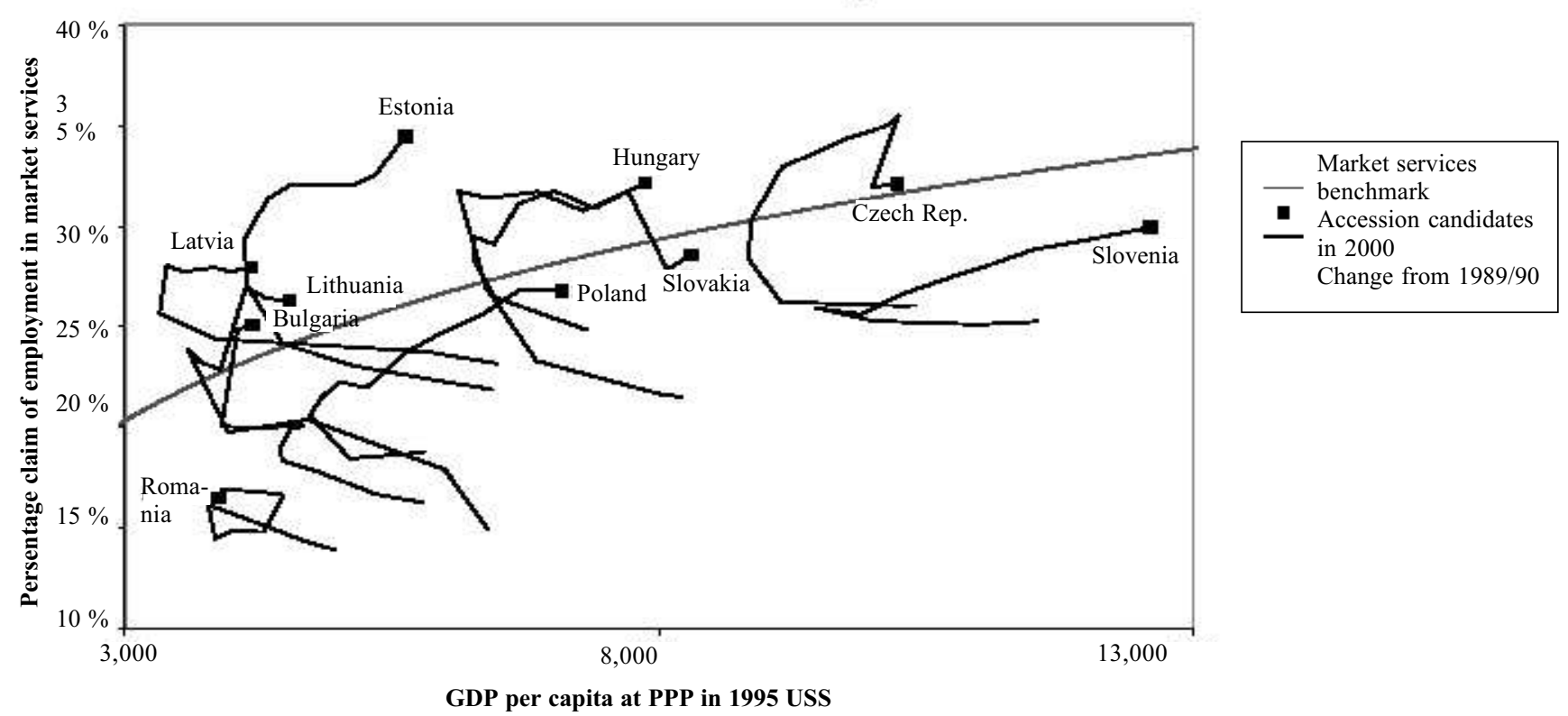

Fig 3. Dynamics of services employment in Accession Candidates in 2000 and change from pre-transition.

Market-oriented services were under-provided in years of central planning. It is expected that labor force in transition countries should move into this sector. Figure 3 shows that all countries have moved towards the market economy benchmark, but not all have increased the share of labor in market services. All the transition economies started the transition with small market-oriented service sectors. Most of the poorest transition countries, however, didn't adjust in this respect. They moved closer to the benchmark by keeping roughly the same market service size and simply becoming poorer. Lithuania as well as most of the middle-ranking countries, adjusted for transition by increasing the share of employment in services. This is shown through the upward movements in the figure. In fact, Lithuania's employment share in services exceeds that of benchmark implying about country's progress in developing its economic structure, despite of relatively low GDP per capita level.

\section{Statistical testing of Lithuanian structural development tendencies' implications}

Impact of Lithuanian economical restructurng expressed in terms of employment share in agriculture, industry and services on GDP growth was statistically tested by simple correlation analysis. The results were as follows:

1. Negative and statistically significant (tested with Student coefficient) correlation coefficient $(-0,87)$ was for agriculture variable $\left(\mathrm{x}_{1}\right)$ showing that decrease of GDP share in agriculture sector induces upward GDP fluctuation. Decreasing share of agriculture production in GDP is commensurate with low labor productivity in this sector. Employment contraction, observed in last 10 years wasn't followed by progress in labor productivity. Lack of domestic and foreign investment dampening implementation of agricultural reform could plausibly account for productivity „lock in“.

2. There was no significant correlation (correlation coefficient - 0,16), approving the impact of changes in industrial GDP share on total GDP. Although industrial sector covers almost 30\% of country's employment and production and is a major exporter, insignificant correlation implies of possible export structure deviation towards maintaining unproductive and lowvalue-added industrial sectors, which doesn't assure positive contribution towards country's economic growth.

3. Positive correlation (correlation coefficient 0,69 ), although statistically insignificant is found between increasing GDP share in service sector and total GDP. Positive correlation coincide with theoretical pattern of country's economic development, which emphasize expansion of service sector as country reaches overindustrialization stage. Although taking into consideration all acceding candidates, Lithuania lags behind in developing its services and accounts for the smallest production and employment share in this sector, what indicates some prospects for expansion of sector. 
Generalizing presented elaborations, we would like repeatedly to put emphasis on the following findings. As it was shown, consistent patterns of development rather significantly affect structural developments of developed and transition countries. Statistical testimonies on Lithuanian pattern verify those theoretical findings.

Problem with "benchmarking" of economic structures is that the cross-country patterns of development patterns hardly are stable over time. Therefore, they can give only rather approximate view of efficient structure of developing country. Another shortcoming of benchmarking is that it in principle can not account for specialization in global market, availability of natural and other resources, size country, demographic trends pace and efficiency of technological spillovers, state policy etc. Hence, constructing of economical policy of transition country in field of relocation of its recourses should take into account consistent patterns of structural development but not stick to concrete benchmark.

\section{Conclusions}

Structure of economy is to be perceived as significant determinant of macroeconomic development and growth of any country. Distinctive feature of centrally planned economies was the degree of overindustrialization, compared with market economies at similar per capita income.

Evidence for the industrial countries suggests that the share of production in GDP changes according inverse "U" shape pattern: at first reaches its peak ant later starts to fall down, it means country starts to deindustrialize. As economies grow richer, the share of services in GDP and employment rises and share of agriculture and employment falls. Statistical testimonies on Lithuanian pattern verify those theoretical findings.

The conclusion we can draw is, that post-communist countries as being overindustrialized in the start of transition inevitably will move towards diminished industry share.

A lot of scientific works are devoted to benchmarking of restructuring of transition countries. The most popular approach is based on opinion that structure of transition countries should converge to structure of market economy country with the same level of GDP per capita.

One problem with "benchmarking" is that the crosscountry patterns of development patterns hardly are stable over time. Therefore, they can give only rather approximate view of efficient structure of developing country. Another shortcoming of benchmarking is that it, in principle, can not account for specialization in global market, availability of natural and other resources, size country, demographic trends pace and efficiency of technological spillovers, active state policy, and efficiency of reforms.

Economical policy of transition country in field of relocation of its recourses should take into account consistent patterns of structural development but not stick to concrete benchmark.

\section{References}

1. Cornwall, J.; Cornwall, W. A demand and supply analysis of productivity growth. Structural Change and Economic Dynamics, Volume 13, Issue 2, June 2002, p. 203-229.

2. European Bank for Reconstruction and development (EBRD) Transition report, 1996-1999.

3. Griffits, Wall, Applied Economics, 2001, p. 2.

4. $\mathrm{Hu}, \mathrm{B} . ; \mathrm{McAleer}, \mathrm{M}$. Input-output structure and growth in China. Mathematics and Computers in Simulation, MSSANZ/IMACS $14^{\text {th }}$ Biennial Conference on Modelling and Simulation, Volume 64, Issue 1, 5 January 2004, p. 193-202.

5. Ishikawa, J. Learning by doing, changes in industrial structure and trade patterns, and economic growth in a small open economy. Journal of International Economics, Volume 33, Issues 3-4, November 1992, p. 221-244.

6. Jackman, R.; Pauna. Labour Market Policy ad the Reallocation of Labour across Sectors, London School of Economics, Mimeo, 1995.

7. Mickiewitz, T.; Zalewska, A. Deindustrialization. Lessons from the structural outcomes of post- communist Transition. William Davidson Working Papers Nr. 463, 2002.

8. Raiser, M.; Schaffer, M.; Schuchardt, J. Benchmarking structural change in transition. Structural Change and Economic Dynamics, Volume 15, Issue 1, March 2004, p. $47-81$.

9. Winiecki, J. The distorted World of Soviet Type Economies, Routledge, London and New York, 1988. 